\title{
IMPLEMENTASI PERMAINAN JEPIT BAJU UNTUK MENINGKATKAN HAFALAN HURUF HIJAIYAH KELOMPOK A DI RA NURUR RAHMAH SUMBER ANYAR MLANDINGAN
}

\author{
Fatimatus Zahro, \\ Pendidikan Islam Anak Usia Dini,Tarbiyah, Universitas Ibrahimy Situbondo \\ E-mail: tzahro205@gmail.com
}

\begin{abstract}
ABSTRAK: Penelitian ini menyajikan tentang penggunaan permainan jepit baju untuk meningkatkan hafalan huruf hijaiyah di RA Nurur Rahmah Kelompok A Sumber Anyar Mlandingan dengan jumlah siswa 14 orang. Tujuan penelitian ini adalah 1) mengetahui proses pelaksanaan permainan jepit baju dalam meningkatkan hafalan huruf hijaiyah. 2) mengetahui hasil pelaksanaan kegiatan bermain dengan menggunakan permainan jepit baju dalam meningkatkan hafalan huruf hijaiyah. Metode yang digunakan adalah dengan menggunakan penelitian tindakan kelas. Penelitian ini menggunakan model dari Carr dan Kemmis dengan menggunakan 4 tahap, yaitu perencanaan, pelaksanaan, observasi dan refleksi. Hasil pada penelitian ini adalah 1) Proses pelaksanaan permainan jepit baju ini di mulai dari anak menjepitkan miniatur baju dengan urut kemudian anak di dampingi guru menyebutkan dan menunjuk huruf hijaiyah. 2) Hasil pra siklus mencapai ketuntasan sebesar $28 \%$. Setelah dilakukan tindakan yaitu dengan menggunakan alat permaian jepit baju diperoleh hasil Siklus I sebesar 64\% dan Siklus II meningkat menjadi 85\%.
\end{abstract}

Kata Kunci: Permainan Jepit Baju; Huruf Hijaiyah

ABSTRACT: This study presents the use of clothes pinning games to improve
memorization of hijaiyah letters in RA Nurur Rahmah Group A Sumber Anyar
Mlandingan with 14 students. The purposes of this study were 1) to know the
process of implementing clothes pinning games in improving memorization of
hijaiyah letters. 2) to find out the results of the implementation of playing
activities by using clothes pinches to improve memorization of hijaiyah letters.
The method used is by using the classroom action research. This study uses a
model from Carr and Kemmis using 4 stages, namely planning,
implementation, observation and reflection. The results of this study are: 1 ) The
process of implementing the clothes pinning game starts from the child
clamping the miniature clothes in order, then the child is accompanied by the
teacher to mention and designate hijaiyah letters. 2) The pre cycle results
reached $28 \%$ completeness. After taking the action, namely by using clothes
pinning clothes, the results of Cycle I were $64 \%$ and Cycle II increased to $85 \%$.

Keywords: Clothes Pinch; Hijaiyah letters 


\section{PENDAHULUAN}

Anak usia dini merupakan periode usia awal yang paling penting dan mendasar dalam sepanjang rentang pertumbuhan serta perkembangan kehidupan. Pada masa ini ditandai oleh berbagai periode penting yang fundamen dalam kehidupan anak selanjutnya sampai periode akhir perkembangannya. salah satu periode penting yang menjadi ciri masa usia dini adalah the golden age atau periode keemasan (Hariyanto, 2013: 6).

Menurut vygotsky bermain mempunyai peran langsung terhadap perkembangan kognisi seorang anak. Vygotsky menekankan pemusatan hubungan sosial sebagai hal penting yang mempengaruhi perkembangan kognitif karena pertama-tama anak menemukan pengetahuan dalam dunia sosialnya, kemudian menjadi bagian dari perkembangan kognitifnya. Permainan dan bermain memiliki arti dan makna tersendiri bagi anak. Permainan mempunyai arti sebagai sarana mensosialkan diri (anak) artinya permainan digunakan sebagai sarana membawa anak ke dalam masyarakat (Mutiah, 2010: 110). Mengenalkan anak menjadi anggota suatu masyarakat, mengenal dan menghargai masyarakat. Permainan sebagai sarana untuk mengukur kemampuan dan potensi diri anak.

Dalam pembelajaran anak usia dini memang diharapkan APE yang memadai jika memang APE yang dimiliki setiap lembaga hanya seadanya maka bagaimana seorang guru harus lebih kreatif menciptakan APE sendiri. Karena sebuah alat permainan edukatif sangat penting untuk anak dan dibutuhkan oleh anak. Mayke Sugianto mengemukakan bahwa alat permainan edukatif (APE) adalah alat permainan yang sengaja dirancang secara khusus untuk kepentingan pendidikan. Pengertian alat permainan edukatif tesebut menunjukkan bahwa pada pengembangan dan pemanfaatannya tidak semua alat permainan yang digunakan anak usia dini itu dirancang khusus untuk mengembangkan aspek-aspek perkembangan anak (Badru, 2014: 54).

Pendidikan anak usia dini merupakan usia yang efektif untuk mengembangkan potensi yang dimiliki anak. Salah satu kemampuan anak yang perlu dikembangkan adalah kemampuan dasar bahasa Arab sebagai bahasa Al-Qur'an. Pada anak usia prasekolah kemampuan bahasa Arab ditekankan pada pengenalan hurufhuruf hijaiyah, dengan media yang tepat agar stimuli yang diberikan dapat terekam pada ingatan anak dengan baik.

Akan tetapi kenyataan di lapangan menunjukkan bahwa masih banyak anakanak khususnya siswa di RA Nurur Rahmah kelompok A yang memiliki keterbatasan menghafal huruf hijaiyah dengan baik dan benar serta proses pembelajaran yang monoton. Metode pembelajaran yang digunakan guru kurang menarik dan kurangnya penggunaan media yang ada, sehingga anak merasa bosan dan kurang termotivasi untuk menerapkan apa yang telah disampaikan.

Oleh karena itu dalam usaha mengenalkan huruf hijaiyah pada anak usia dini tidak boleh menuntut penalaran anak akan huruf demi huruf, melainkan penalaran hafalan anak terhadap huruf hijaiyah itu dengan variasi bentuk dan warna yang akan mudah meresap kedalam memori ingatan mereka. Dengan demikian, dalam usaha mengenalkan huruf hijaiyah pada anak usia dini, salah satu media yang dapat dilaksanakan adalah dengan menggunakan alat permainan edukatif (APE) jepit baju.

\section{METODE PENELITIAN}

Penelitian ini adalah menggunakan penelitian tindakan kelas. Penelitian ini digunakan untuk memahami tentang perkembangan anak dan sebagai upaya untuk meningkatkan kemampuan menghafal huruf hijaiyah di kelompok A. Penelitian tindakan kelas ini dapat membantu guru menjembatani jurang 
antara teori dan praktik. Guru dapat menguji keyakinan yang ada di dalam dirinya pada penelitian tindakan kelas yang dilaksanakannya. Kurt Lewin menyatakan bahwa ada empat hal yang harus dilakukan dalam proses penelitian tindakan yaitu perencanaan (Planning), tindakan (Action), observasi (Observation) dan refleksi (Reflection) (Sanjaya, 2009: 49).

Tabel 1. Rekapitulasi Hasil Observasi Pra Siklus

\begin{tabular}{|l|l|r|r|}
\hline No & \multicolumn{1}{|c|}{ Kategori } & $\begin{array}{c}\text { Jumlah } \\
\text { Anak }\end{array}$ & $\begin{array}{c}\text { Pra } \\
\text { Siklus }\end{array}$ \\
\hline 1. & Tuntas & 4 & $28 \%$ \\
\hline 2. & Belum tuntas & 10 & $72 \%$ \\
\hline \multicolumn{2}{|c|}{ Jumlah Total } & 14 & $100 \%$ \\
\hline
\end{tabular}

Subjek penelitian dilakukan pada anak usia dini kelompok A. Dengan jumlah peserta didik 14 siswa yaitu siswa laki-laki berjumlah 5 dan perempuan berjumlah 9 siswi. Sedangkan lokasi penelitian bertempat disekolah RA Nurur Rahmah Sumber Anyar Kecamatan Mlandingan Kabupaten Situbondo. Objek penelitian pelaksanaan permainan jepit baju dalam meningkatkan hafalan huruf hijaiyah anak.

\section{HASIL PENELITIAN \\ Observasi Pra Siklus}

Peneliti melakukan observasi melalui diskusi dan wawancara dengan kepala sekolah, guru kelas dan anak kelompok A di RA Nurur Rahmah Sumber Anyar Mlandingan untuk mengetahui bagaimana kegiatan pembelajaran di RA Nurur Rahmah khususnya di kelompok A. Dalam kegiatan pembelajaran di RA Nurur Rahmah menggunakan klasikal yaitu baca dan hitung. Setelah peneliti masuk kelas ditemukan bahwa masih banyak anak-anak di kelompok A yang belum mampu menghafal huruf hijaiyah dengan baik dan benar. Ada dua anak yang sudah menghafal dan mengenal huruf hijaiyah, ada juga dua anak yang sudah menghafal tapi belum mengenal. Karena pembelajaran yang diterapkan di kelompok A ini tidak menggunakan permainan yang dapat merangsang anak untuk lebih santai dan lebih tenang dalam proses pembelajaran.

Berdasarkan hasil diskusi dan wawancara, peneliti mengambil langkah untuk meningkatkan hafalan huruf hijaiyah. Tindakan yang akan dilakukan adalah melaksanakan pembelajaran hafalan melalui permainan jepit baju. Melalui adanya permainan jepit baju tersebut diharapkan anak dapat senang dan tenang dalam belajar dan dapat meningkatkan hafalan huruf hijaiyah I sampai ض.

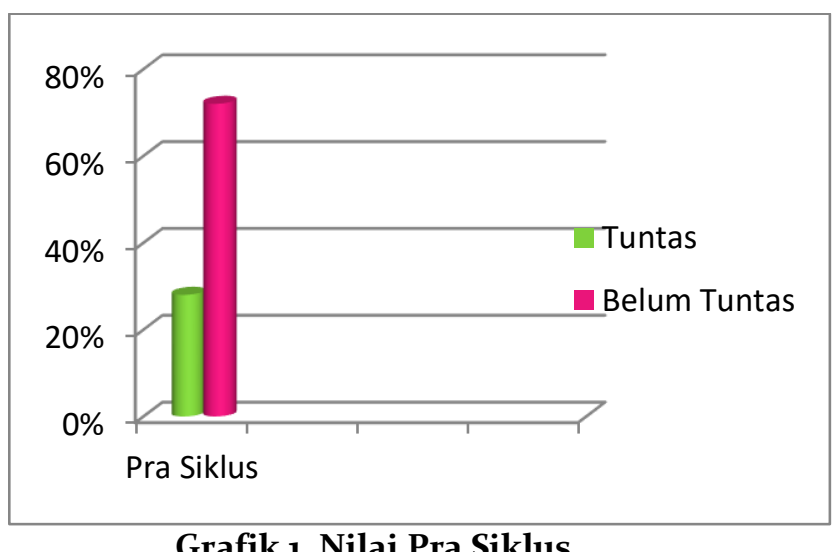

\section{Siklus I}

Untuk mengetahui hasil dari permainan yang akan di gunakan dalam penelitian ini dengan permainan jepit baju. Dalam siklus I ada empat tahap yaitu:

a. Tahap Perencanaan

Perencanaan merupakan tindakan yang akan dilakukan oleh peneliti pada tahap awal penelitian yaitu dengan mempersiapkan segala keperluan dan langkah-langkah dalam melakukan penelitian. Dalam tahap ini peneliti menyiapkan persiapan-persiapan seperti 
melakukan koordinasi dengan guru RA Nurur Rahmah mengenai APE jepit baju pada saat proses belajar, menyusun Rencana Pelaksanaan Pembelajaran Harian (RPPH), menyiapkan bahan/media yang akan digunakan pada kegiatan belajar huruf hijaiyah dengan permainan jepit baju dan menyiapkan lembar observasi.

b. Tahap Pelaksanaan

Tahap pelaksanaan merupakan penerapan permainan jepit baju yang bertujuan untuk meningkatkan hafalan huruf hijaiyah anak kelompok A di RA Nurur Rahmah. Kegiatan pelaksanaan pembelajaran Siklus I sesuai dengan rencana pelaksanaan pembelajaran harian (RPPH).

\section{c. Observasi}

Guru menginformasikan tentang tema dan sub tema pada hari itu. Setelah waktu istirahat berlalu kegiatan penutup dimulai membaca do'a sesudah makan dan minum. Setelah recalling selesai anak-anak di ajak merapikan mainan setelah itu ustadzah menginformasikan kegiatan esok harinya, menghitung dari angka 1-10 dengan tiga bahasa, do'a setelah belajar menyanyikan huruf hijaiyah, salam, pulang. Peneliti menilai hari ini anak kelompok A semangatnya sangat luar biasa karena mereka bermain dengan permainan baru. Peneliti berdiskusi dengan guru kelas dan kepala sekolah tentang hasil dari penelitian siklus I ke dalam tabel.

Tabel 2. Rekapitulasi Hasil Observasi Pada Siklus I

\begin{tabular}{|l|l|r|r|}
\hline No. & Kategori & $\begin{array}{c}\text { Jumlah } \\
\text { Anak }\end{array}$ & Siklus I \\
\hline 1. & Tuntas & 9 & $64 \%$ \\
\hline 2. & Belum tuntas & 5 & $36 \%$ \\
\hline
\end{tabular}

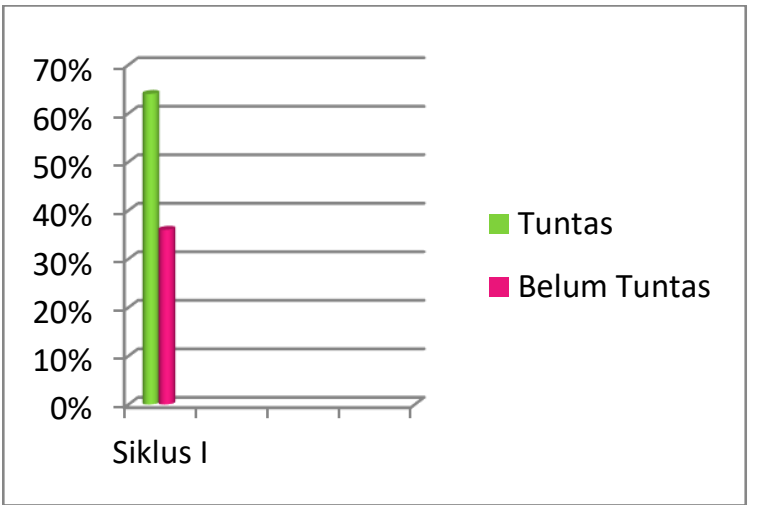

Grafik 2. Nilai Pencapaian Anak Siklus I

d. Refleksi

Berdasarkan data hasil observasi yang diperoleh serta pengamatan peneliti pada siklus I, maka peneliti melakukan refleksi terhadap seluruh kegiatan yang telah dilakukan oleh anak, yang hasilnya antara lain:

1) Pada awal kegiatan ini anak memiliki respon yang baik terhadap peneliti yang akan memberikan pembelajaran pada anak.

2) Anak belum bisa / merasa kebingungan dalam mengurutkan dengan baik huruf hijaiyah

3) Guru tidak mengarahkan peserta didik ketika bermain mereka dapat melihat urutan huruf hijaiyah di papan.

4) Pada saat kegiatan inti berlangsung, peneliti melihat masih ada beberapa anak tempat duduknya tidak rapi dan mengganggu temannya untuk bermain duluan.

Ada beberapa hal yang perlu diperbaiki dalam siklus II antara lain: guru akan mengarahkan peserta didik dalam hal mengurutkan susunan huruf hijaiyah dengan benar. Penataan tempat duduk yang awalnya peserta didik duduk lurus membentuk lingkaran agar anak tidak berpindah-pindah tempat untuk melihat permainan jepit baju sehingga kondisi saat proses berlangsung lebih kondusif.

\section{Siklus II}

Dalam perbaikan di siklus II ini hal pertama yang akan dilakukan penataan tempat dan menjelaskan kembali cara bermain permainan jepit baju tersebut. 
Guru juga menjelaskan kepada peserta didik delapan indikator yang harus di capai.

a. Tahap Perencanaan

Perencanaan merupakan tindakan yang akan dilakukan oleh peneliti pada tahap awal penelitian yaitu dengan mempersiapkan segala keperluan dan langkah-langkah dalam melakukan penelitian. Dalam tahap ini peneliti menyiapkan persiapan-persiapan seperti,

\begin{tabular}{|l|l|r|r|}
\hline No & \multicolumn{1}{|c|}{ Kategori } & $\begin{array}{c}\text { Jumlah } \\
\text { Anak }\end{array}$ & Siklus II \\
\hline 1. & Tuntas & 12 & $85 \%$ \\
\hline 2. & Belum Tuntas & 2 & $15 \%$ \\
\hline \multicolumn{2}{|c|}{ Jumlah Total } & 14 & $100 \%$ \\
\hline
\end{tabular}

membuat rencana pelaksanaan kegiatan, menyusun Rencana Pelaksanaan Pembelajaran Harian (RPPH), menyiapkan bahan/media yang akan digunakan pada kegiatan belajar huruf hijaiyah dengan permainan jepit baju dan menyiapkan lembar observasi.

\section{b. Tahap Pelaksanaan}

Kegiatan pelaksanaan pembelajaran Siklus II sesuai dengan rencana pelaksanaan pembelajaran harian (RPPH) dengan kegiatan belajar huruf hijaiyah dengan permainan jepit baju dimulai pada kegiatan awal, kegiatan inti, istirahat, dan kegitan penutup pada pembelajaran.

c. Observasi

Dengan melihat kondisi kegiatan siklus I yang masih kurang berhasil, maka guru melakukan tindakan kelas lanjutan yakni siklus II. Siklus II ini dilakukan bertujuan untuk memperbaiki hafalan huruf hijaiyah anak kelompok A. Sebelum memulai kegiatan inti ustadzah tema dan sub temanya yaitu " pekerjaan" sub tema "petani" Dalam tahap ini peneliti siklus II ini peneliti meminta izin sebelumnya kepada ustadzah bertindak sebagai guru untuk menjelaskan hal-hal berikut :

1) Menyampaikan tujuan pembelajaran dan menginformasikan media pembelajaran.
2) Memberitahukan kegiatan yang akan dilakukan kepada anak.

3) Mengubah tempat duduk yang awalnya lurus menjadi lingkaran agar tidak terjadi keributan seperti pada siklus I

4) Bertanya kepada anak tentang belajar huruf hijaiyyah dengan permainan jepit baju

5) Memberikan kesempatan kepada anak untuk bertanya.

Seluruh anak terlihat antusias dalam melaksanakan kegiatan pembelajaran yang diberikan oleh peneliti. Jika dilihat dari hafalan huruf hijaiyyah anak pada saat menggunakan permainan jepit baju, anak sudah banyak mengalami perubahan yang lebih baik.

Tabel 3. Pencapaian Ketuntasan Anak Siklus II

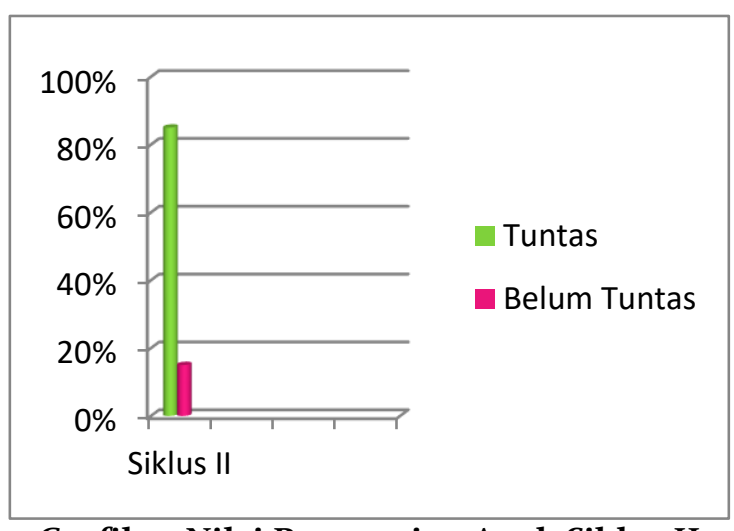

Grafik 3. Nilai Pencapaian Anak Siklus II

Sesuai data di atas dalam siklus II ini peneliti merasa sempurna dengan nilai yang di dapatkan peserta didik. Namun masih ada dua anak yang belum tuntas. Jumlah anak yang tuntas 12 orang dengan nilai $85 \%$ menurut peneliti sudah melebihi target yang peneliti tentukan untuk penilaian dengan menngunakan permainan jepit baju. Dengan hasil yang di capai dalam siklus II ini peneliti cukupkan karena sudah mencapai target dan tidak perlu melaksanakan siklus selanjutnya.

d. Refleksi

Dalam pelaksanaan siklus II ini menurut peneliti nilai yang didapatkan 
peserta didik sudah memenuhi Kriteria Capaian Pembelajaran (80\%). Maka permainan jepit baju ini sangat membantu peneliti dalam melakukan penelitian dalam siklus II. Dalam pelaksanaan siklus I masih perlu adanya perbaikan dalam mengarahkan anak didik ketika bermain. Nilai yang didapatkan di siklus I yang tuntas 9 anak (64\%) yang belum tuntas 5 anak (36\%). Maka di siklus II ini peneliti mencoba untuk memperbaikinya dan hasilnya sangat memuaskan sesuai dengan target yang peneliti harapkan. Anak yang tuntas dalam siklus II ini 12 anak (85\%) dan belum tuntas 2 orang (15\%). Seluruh anak terlihat antusias dalam melaksanakan kegiatan pembelajaran yang diberikan oleh peneliti. Jika dilihat dari hafalan huruf hijaiyyah anak pada saat menggunakan permainan jepit baju, anak sudah banyak mengalami perubahan yang lebih baik. Berdasarkan hasil reflaksi pada siklus ini sudah dianggap cukup dan tidak perlu diadakan siklus atau tindakan selanjutnya.

\section{PEMBAHASAN}

\section{Proses Pelaksanaan Permainan Jepit Baju}

Sebelum peneliti melakukan siklus I dan siklus II yang dilaksanakan oleh peneliti adalah observasi pra siklus. Dalam observasi ini peneliti mengamati kegiatan pembalajaran di dalam kelas. Metode yang digunakan guru di RA Nurur Rahmah adalah klasikal tanpa menggunakan permainan yang bisa membuat peserta didik senang dan santai.

Guru menjelaskan terlebih dahulu cara bermain yaitu dengan menjepitkan satu jepitan digunakan untuk satu baju dan mengarahkan peserta didik melihat urutan huruf hijaiyah yang telah ditulis oleh guru di papan tulis. Permainan jepit baju dimulai dari dua anak yang bermain secara perorangan dan bergantian dengan temannya yang lain setelah selesai bermain. Dengan menjepitkan miniatur baju sambil lalu melihat urutan huruf hijaiyah di depan lalu peserta didik di suruh menyebut dan menunjuk huruf hijaiyah sesuai dengan perintah guru, tidak hanya huruf hijaiyah guru juga menanyakan tentang warna yang ada di baju tersebut agar anak dapat mengenal warna.

Pada saat kegiatan inti berlangsung, peneliti melihat masih ada beberapa anak tempat duduknya tidak rapi dan mengganggu temannya untuk bermain duluan sehingga anak gaduh, berebut, karena di waktu itu anak baru pertama kali belajar menggunakan APE jepit baju. Maka peneliti merancang kembali untuk melakukan siklus II. Hal pertama yang dilakukan peneliti untuk perbaikan dalam siklus I ini adalah merapikan tempat duduk anak dan menatanya agar kesalahan tidak terjadi di siklus II. kedua adalah guru mengarahkan anak didiknya agar dapat mengurutkan huruf hijaiyah dengan benar.

Keunggulan permainan jepit baju ini mempermudah anak dalam menghafal huruf hijaiyah. Permainan jepit baju ini di mulai dari anak menjepitkan miniatur baju dengan urut kemudian anak di dampingi guru menyebutkan dan menunjuk huruf hijaiyah. Selain menyebut dan menunjukkan huruf hijaiyah peneliti juga menambahkan warna agar anak juga dapat mengenal warna.

Hasil Pelaksanaan Permainan Jepit Baju Berdasarkan hasil observasi yang telah dilakukan pada pertemuan awal (pra siklus). Peneliti menilai bahwa ada 4 orang anak yang sudah bisa menghafal huruf hijaiyah dan masih ada 10 anak yang di katakan belum menghafal huruf hijaiyah. Dari observasi pra siklus peneliti menggunakan presentase data diperoleh hasil $28 \%$ dengan nilai rata-rata 4. Untuk itu peneliti merancang kegiatan sebelum melakukan siklus I.

Dalam melakukan penelitian siklus I peneliti menggunakan permainan jepit baju ini untuk meningkatkan hafalan huruf hijaiyah anak. Berdasarkan hasil penelitian siklus I selama proses pembelajaran yang dilakukan oleh peneliti diketahui bahwa selama proses pembelajaran, terlihat bahwa secara keseluruhan belum mencapai 
Ketuntasan Capaian Pembelajaran. Hal ini dibuktikan oleh hasil pengamatan diperoleh nilai rata-rata sebesar (6). Oleh sebab itu, peneliti harus melanjutkan untuk siklus yang ke II.

Pada siklus I tingkat pencapaian kesuksesan mencapai 64\%. Hal ini disebabkan karena peserta didik masih kebingungan dalam mengurutkan huruf hijaiyah karena guru tidak mengarahkan peserta didik untuk melihat ke papan saat bermain. Pada siklus yang ke II diperoleh nilai rata-rata secara keseluruhan adalah sebesar (7) dengan kategori sangat baik. Penerapan pembelajaran permainan jepit baju di kelompok A RA Nurur Rahmah sudah sangat efektif, aktif dan kreatif. Hal ini sesuai dengan teori yang dikemukakan oleh Gagne dan Briggs dimana media atau model pembelajaran merupakan komponen sumber atau wahana fisik yang mengandung materi instruksional dilingkungan siswa yang dapat merangsang siswa untuk belajar.

Pada siklus II ini mengalami peningkatan disebabkan karena anak mulai bisa bersabar menunggu giliran, perbaikan tempat duduk dan guru mengarahkan anak didiknya dalam mengurutkan huruf hijaiyah. Dalam siklus II ini tingkat pencapaian anak meningkat hingga mencapai $85 \%$ dari 14 anak. Hal ini terbukti dengan melihat kriteria ketuntasan individu yang terdiri dari 8 indikator yaitu, di katakan tidak tuntas apabila anak mencapai 1-4 indikator dan dikatakan tuntas bila mencapai 5-8 indikator.

Tabel 4. Hasil Presentase Tindakan Siklus I dan Siklus II

\begin{tabular}{|c|l|c|c|}
\hline No. & Pencapaian & Siklus I & $\begin{array}{c}\text { Sikl } \\
\text { us II }\end{array}$ \\
\hline 1. & $\begin{array}{l}\text { Pencapaian } \\
\text { Klasikal }\end{array}$ & $64 \%$ & $85 \%$ \\
\hline
\end{tabular}

\begin{tabular}{|c|c|c|c|c|c|c|}
\hline \multicolumn{2}{|l|}{2.} & \multicolumn{2}{|c|}{ Nilai Rata-Rata } & \multicolumn{2}{|c|}{6} & 7 \\
\hline \multirow{2}{*}{$\begin{array}{c}\text { Kateg } \\
\text { ori } \\
\text { Nilai }\end{array}$} & \multicolumn{3}{|c|}{$\begin{array}{r}\text { Jumlah } \\
\text { anak }\end{array}$} & \multicolumn{3}{|c|}{ Prosentase } \\
\hline & $\begin{array}{c}\text { Pra } \\
\text { Sikl } \\
\text { us }\end{array}$ & $\begin{array}{c}\text { Sik } \\
\text { lus } \\
\text { I }\end{array}$ & $\begin{array}{c}\text { Sik } \\
\text { lus } \\
\text { II }\end{array}$ & $\begin{array}{c}\text { Pra } \\
\text { Sikl } \\
\text { us }\end{array}$ & $\begin{array}{l}\text { Sikl } \\
\text { us I }\end{array}$ & $\begin{array}{c}\text { Sik } \\
\text { lus } \\
\text { II }\end{array}$ \\
\hline Tuntas & 4 & 9 & 12 & $28 \%$ & $64 \%$ & $\begin{array}{l}85 \\
\%\end{array}$ \\
\hline $\begin{array}{l}\text { Belum } \\
\text { Tuntas }\end{array}$ & 10 & 5 & 2 & $72 \%$ & $36 \%$ & $15 \%$ \\
\hline
\end{tabular}

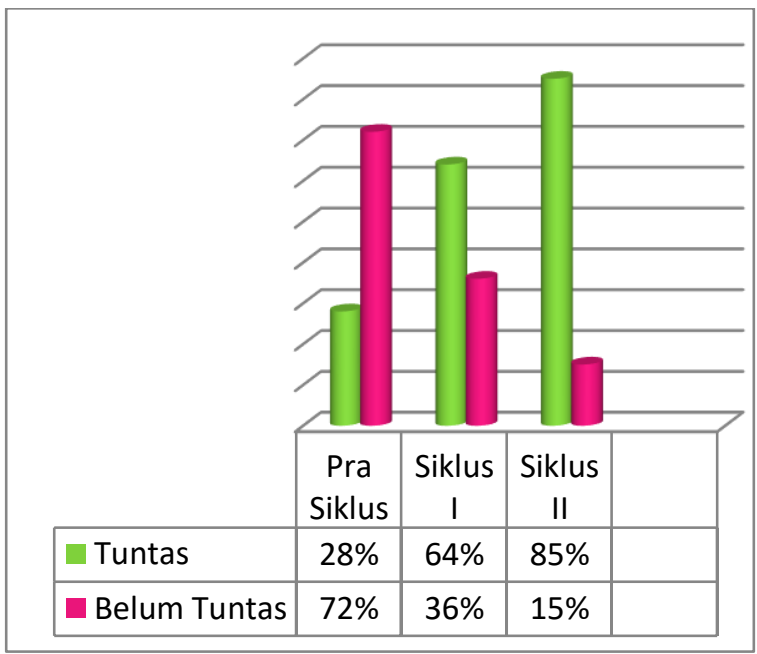

Grafik 4. Hasil Presentase Pra Siklus, Siklus I dan Siklus II

Menurut tabel diatas dapat dilihat dari hasil presentase pra siklus $28 \%$ yaitu 4 anak. Siklus I dengan hasil $64 \%$ yaitu 9 anak dan siklus II dengan hasil 85\% yaitu 12 anak. Maka dapat di jelaskan dalam siklus I mendapatkan hasil yang kurang maksimal tapi siklus II mendapatkan hasil yang sangat bagus. Dengan permainan jepit baju ini diharapkan membantu anak untuk meningkatkan hafalan huruf hijaiyah.

\section{KESIMPULAN}

Penggunaan permainan Permainan jepit baju yang peneliti terapkan untuk meningkatkan hafalan huruf hijaiyah anak kelompok A. Dalam bentuk pelaksanaan peneliti membuat delapan indikator. 
Permainan jepit baju dimulai dari dua anak yang bermain secara perorangan dan bergantian dengan temannya yang lain setelah selesai bermain. Dengan menjepitkan miniatur baju sambil lalu melihat urutan huruf hijaiyah di depan lalu peserta didik disuruh menyebut dan menunjuk huruf hijaiyah sesuai dengan perintah guru, tidak hanya huruf hijaiyah guru juga menanyakan tentang warna yang ada di baju tersebut agar anak juga dapat mengenal warna. Dan terakhir guru menghargai semangat anak dengan memberikan pujian dan sebagainya agar lebih termotivasi.

Dari data yang telah disajikan, bahwa dengan menggunakan alat permainan jepit baju dapat meningkatkan hafalan huruf hijaiyah. Hal ini dibuktikan dengan adanya peningkatan dari Pra Siklus yang rata-rata pencapaian kelas bernilai $28 \%$ meningkat pada Siklus I yang rata-rata pencapaian kelas bernilai $64 \%$, ditambah lagi adanya peningkatan pada Siklus II dimana rata-rata pencapaian kelas bernilai 85\%. Jadi dengan menggunakan alat permainan edukatif jemuran baju terbukti dapat meningkatkan aktivitas dan hafalan pada anak usia dini di RA nurur rahmah dengan sangat baik. Dibuktikan dengan adanya persentase data perbandingan antara Pra Siklus, Siklus I dan Siklus II.

\section{DAFTAR PUSTAKA}

Yahya, Abdul Fattah. 2015. Revolusi Menghafal Alqur'an. Surakarta: Insan Kamil.

Baduwailan, Ahmad. 2016. Menjadi Hafizh: Tips dan Motivasi Menghafal Alqur'an, vol. 2. Solo: Aqwam.

Departemen Pendidikan Nasional. 2012. Kamus Besar Bahasa Indonesia, Jakarta: Gita Media Press.

Hariyanto. 2013. Edutaiment Pendidikan Anak Usia Dini, Jember: Pena Salsabila.

Harozi, Muhammad. 20o8. Buhgyatul Murid Min Ahkamit Tajwid, Bairut: Hataf Fakas.
Huda, Nurul. 2012. Tokcer Bahasa Arab, Jogyakarta: Bening.

Kurnaedi, Abu Ya'la dan Sa'ad Jabal Nizar. 2010. Metode Asy-Syafi'i: Cara Praktis Baca Al-Qur'an dan Ilmu Tajwid, Jakarta: Pustaka Imam AsySyafi'i.

Muhsin, Abdul \& Raghib. 2014. Orang Sibuk Pun Bisa Hafal Alqur'an, Solo: PQS Publishing.

Muhyiddin. 2012. Sekilas Sejarah Tulisan Arab, Kediri: Semprulle.

Musfiroh, Tadkiroatun dan Tatminingsih Sri. 2015. Bermain dan Permainan Anak Banten: Universitas Terbuka.

Mutiah, Diana. 2010. Psikologi Bermain Anak Usia Dini, Jakarta: Kencana

Susanto, Ahmad. 2011. Perkembangan Anak Usia Dini, Jakarta: Kencana.

Syaukani, Et All. 2002. Otonom Daerah dalam Negara Kesatuan, Yogyakarta: Pustaka Belajar Offset

Tedjasaputra, S Mayke. 2001. Bermain dan Permainan, Jakarta: Grasindo.

Tekan, Ismail. 2004. Tajwid Al-Qur'anul Karim, Jakarta: Pustaka Al Husna Baru.

Widodo, et all. 2001. Kamus Ilmiah Populer, Yogyakarta: Absolut.

Zaman, Badru dan Hermawan Asep Hery. 2014. Media E Sumber Belajar Paud, (Tanggerang Selatan: Universitas Terbuka. 